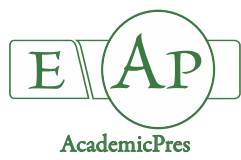

\title{
Total Phenol, Antioxidant and Allelopathy Assay, and Meiosis Study of Lampranthus spectabilis and Aptenia cordifolia
}

\author{
Babak Delnavaz HASHEMLOIAN*, Azra Ataei AZIMI, \\ Reza REZAKANLOU \\ University of Islamic Azad, Saveh Branch, Faculty of Agriculture, Department of Biology, Noralibake Street, Saveh, \\ Iran; Hashemloian1343@gmail.com (“correspondingauthor); ataeiazraazimi@gmail.com; rezakhanlou1397@gmail.com
}

\begin{abstract}
Lamperanthus spectabilis and Aptenia cordifolia (Aiozaceae) are two ornamental plants. A little information is available about their active compounds and meiosis' process. In this study, the phenolic content, antioxidant activity, allelopathy effects and meiosis' process of pollen mother cells of L. spectabilis and A. cordifolia were studied. The alcohol extract was used for phenol, antioxidant and allelopathy assay along with young buds for meiosis study. The stamens and petals of both plants possessed the highest phenol and antioxidant effects. All extracts of L. spectabilis and A. cordifolia had small inhibitory effects on mungbeen seed germination and seedlings growth. The allelopathy effect of both plants on barley seed germination and seedlings growth was significant especially for $A$. cordifolia. The count of chromosomes in meiosis revealed that the chromosome number of $A$. cordifolia was $2 n=12$ and $2 n=18$ for $L$. spetabilis. The meiosis in both plants was normal and the chromosomes were very small. Our results revealed that the extracts of all organs of both plants; specially stamens and petals, have a lot antioxidant activity. They had not allelopathic effects on seed germination' and seedlings growth' mungbeen and barley. Chromosome number of two plants was different but meiosis process and chromosomes size was similar.
\end{abstract}

Keywords: active compounds; barley; chromosomes; germination; mungbean

\section{Introduction}

Aptenia cordifolia (L. fill) and Lampranthus spectabilis (N.E.Br) belonging to Aiozaceae family, are two glabrous perennials and succulent plants (Dellagareca et al., 2007). L. spectabilis (syn: Mesembryanthemum spactabile) is commonly known as a fig marigold (Braun and Winkelmann, 2016; Park et al., 2016). Heptadecyl caffeic acid and 2-(2-hydroxyethyl)-3-methyl fumaric acid from the aerial parts of $L$. spectabilis, did not prove to have a significant antioxidant activity or cytotoxicity on a lung cancer cell line (Samy et al., 2018). L. francisci is an ornamental succulent plant. The hydro-alcohol extracts of L. francisci caused hemolysis of sheep cells and had a fungicidal activity (Moyo and Mukanganyama, 2015).
Betalines from phenolic compounds did not have toxic effects on human (DelgadoVargas et al., 2000) Betalins produce yellow, pink, red and orange colors in different organs Aizoaceae family plants. The betacyanins from betalines as hydroxycininamyl derivatives have been found in Lampranthus sp. flowers (Piatteli and Impellizzer, 1969).

Antioxidants are compounds that inhibit oxidation. Oxidation is a chemical reaction that can produce free radicals, thereby leading to chain reactions that may damage the cells of organisms (Xiao et al., 2019). Allelochemical compounds can be classified into organic acid, alcohols, long chain fatty acids, terpenoids, phenols, alkaloids and lactones (Li et al., 2010). Meiosis is a special type of cell division that reduces the chromosome. In plant sexual reproduction, normal meiosis of pollen grains is the most important factor of pollen fertility. Meiosis I and II stages (prophase, metaphase, anaphase and telophase) and chromosome behavior studies can be determined for normalized pollen. For this, studies have been still focusing on chromosome behavior during meiosis I and II stages through light microscopy and record the results with pictures (GopalaKrishnan et al., 1964). 
1360

Materials and Methods

\section{Plant material}

Shoots of $L$. spectabilis and A. cordifolia were trimmed from around the area of agriculture faculty of Azad university of Saveh.

\section{Alcoholic extraction and total phenol}

A total of $20 \mathrm{~g}$ of each organ (stems, leaves, petals, ovaries and stamens) of fresh plants were mixed with $100 \mathrm{ml}$ ethanol $60 \%$, stored in a bath $60^{\circ} \mathrm{C}$ for 2 hours and filtered. The alcoholic extracts were concentrated using vacuum rotary evaporator, at $60{ }^{\circ} \mathrm{C}$. They were used to measuring the total phenol, antioxidant activity, and allelopathic effects. Folin- Ciocalteu' reagent was used for total phenol determination (Singleton and Rossi, 1965). In $0.5 \mathrm{ml}$ of the each sample, $2.5 \mathrm{ml}$ of diluted Folin-Ciocalteu' reagent $(1 / 10 \mathrm{v} / \mathrm{v})$ was added. After $5 \mathrm{~min}, 2 \mathrm{ml}$ of aqueous $\mathrm{Na}_{2} \mathrm{CO}_{3}$ solution $(1 \mathrm{M})$ was added. The solution was stirred gently and incubated in a water bath at $45^{\circ} \mathrm{C}$ for 15 minutes. Calibration curve was obtained from different concentrations of galic acid $(0-250 \mu \mathrm{g} / \mathrm{ml})$ by spectrophotometery at $765 \mathrm{~nm}$.

\section{Antioxidant}

The antioxidant activities of the organs extracts of $L$. spectabilis and $A$. cordifolia were determined using 2, 2diphenyl-1-1- picrylhyydrazyl (DPPH) (Ibtissem et al., 2009). The extracts were dissolved in alcohol. In $1 \mathrm{ml}$ of the DPPH $(0.1 \mathrm{mM})$ in ethanol, $2 \mathrm{ml}$ of different concentrations $(0.05-0.1 \mathrm{mg} / \mathrm{ml})$ of the extract was added. The solution was incubated in the dark at $25^{\circ} \mathrm{C}$ for 30 minutes. The absorbance was obtained using a UV-VIS spectrophotometer (Shimatzu/JAP), at $517 \mathrm{~nm}$. The percentage of DPPH scavenging activity was calculated using the following formula:

$$
\% \text { Antioxidant }=\left[\frac{\text { ABScontrol }- \text { ABS sample }}{A B S \text { control }}\right] \times 100
$$

\section{Allelopathy}

A total of 10 seeds of barley or mungbean were cultured in a Petri dish with $3 \mathrm{ml}$ extract $(0-0.1 \mathrm{mg} / \mathrm{ml})$ and incubated at $25^{\circ} \mathrm{C}$, for 5 days in dark. Seed germination was determined as followed: the germinated seeds/ the total seeds. For seedlings growth, radicle and shoot length were measured.

\section{Meiosis}

Young flower buds (3-4 mm long) were used for meiosis study of pollen mother cells. Pollen mother cells of the young anthers of the stamens were stained with 2\% aceto carmine (Sharma et al., 1993).

\section{Statically analysis}

Analysis of variance and comparison of means were done using Tukey test and Minitab software (version 15), respectively.

\section{Results}

\section{Totalphenol}

Total phenol of the organs of L. spectabilis and $A$. cordifolia ranged from 13.44 to $43.12 \mathrm{mg} / \mathrm{g}$ dry weight (DW) (Table 1). The maximum total phenol was present in the petal extract of $A$. cordifolia. Total phenol of petals and stamens of both plants were higher than in their leaves, stems and ovaries. The total phenol difference was significant among all organs of $L$. spectabilis and $A$. cordifolia but no significant difference was observed between the two plants except for petals (Table 1).

\section{Antioxidant}

The alcohol extracts of all organs of L. spectabilis and $A$. cordifolia had a significant antioxidant activity in both plants (Table 2). The stamens in both plants showed a higher antioxidant activity relative to their leaves, stems, ovaries and petals. The petals revealed a greater antioxidant activity than other organs did, but it was less than that of the stamens.

\section{Allelopathy}

Seed germination of mungbean did not decline with any of the organ extracts of $A$. cordifolia and $L$. spectabilis except for $A$. cordifolia ovary extract (Table 3 ). Growth of seedlings decreased in seeds in contact with alcohol extract. In the seedlings in contact with all extracts of L. spectabilis, the hypocotyl growth increased within $0.14-1.1 \mathrm{~cm}$, except for the stem extract; the hypocotyl growth of mungbean seedlings in contact with leave and stem extracts of $A$. cordifolia significantly declined. The radicles' length decreased for all extracts, except for stamen extracts of both plants (Table 3). Germination of barely seeds significantly diminished with all the extracts of $A$. cordifolia and $L$. spectabilis except for leaf extract of L. spectabilis (Table 4). The germination of the seeds in contact with the stem and petal extracts of both plants dropped by $35-50 \%$. The radicles' length and youngling's length in each extract decreased by $1.3-3 \mathrm{~cm}$ and $2.01-3.05 \mathrm{~cm}$, respectively (Table 4). Seedlings' growth for seeds in contact with alcohol extracts also declined.

\section{Meiosis}

Stage I (Meiosis I): In both plants, in prophase I, coupling of homologous chromosomes and synapse between them was observed. At metaphase I, bivalent chromosomes settled on the cell plate. In anaphase I, homologous chromosomes were separated and shifted towards opposite poles by the spindles. Two groups of chromosomes, each with 9 and 6 dyad chromosomes of $L$. spectabilis and $A$. cordalis respectively, were separated from each other. Two groups of chromosomes were obverted in cell at telophase I.

Stage II (Meiosis II): After telophase I or during prophase II, chromosomes were observed as partially separated due to compaction. 
1361

In metaphase II, the chromosomes compaction continues to reach their most degree of contraction. The single chromosome settled on the cell plate, the two chromatids were adhered together at centromere. At anaphase II, sister chromatids were dissociated and moved by the spindles. As a result, telophase II cells contained four groups of 9 (L. spectabilis) and 6 (for A. cordifolia) newly formed chromosomes. The four groups of chromosomes were expanded and enveloped to form of the haploid nuclei.
The cytoplasm was partitioned by fragmoplast formation in cell plate during cytokinesis, resulting in the formation of tetrad (Fig. 2). Subsequently, the four haploid microspores were separated from each other and continued their development in to mature pollen grains (Fig. 3).

Chromosome number: The number of chromosomes in L. spectabilis and A. cordifolia was $n=9(2 n=18)$ and $n=6$ $(2 n=12)$. The chromosomes were small in both plants (Figs. 1,3).

Table 1. Total phenol of the organs of $L$. spectabilis and A. cordifolia

\begin{tabular}{ccccc}
\hline Plant & Leave & Stem & Petal & Ovary \\
\hline L. spectabilis & $17.32 \mathrm{~d}$ & $23.33 \mathrm{~d}$ & $36.64 \mathrm{~b}$ & $35.32 \mathrm{c}$ \\
A. cordifolia & $16.87 \mathrm{~d}$ & $21.15 \mathrm{~d}$ & $43.12 \mathrm{a}$ & $13.44 \mathrm{e}$ \\
\hline Note: different letters denote significant differences (Turkey test, $\mathrm{P}<0.05)$ & $32.70 \mathrm{c}$ \\
\hline
\end{tabular}

Note: different letters denote significant differences (Turkey test, $\mathrm{P}<0.05$ )

Table 2. Antioxidant effects of the organs of $L$. spectabilis and A. cordifolia

\begin{tabular}{ccccccc}
\hline Plant & $\begin{array}{c}\text { Extract } \\
\mathrm{mg} / \mathrm{ml}\end{array}$ & Leave & Stem & Petal & Ovary & Stamen \\
\hline \multirow{2}{*}{ L. pectabilis } & 0.05 & $28.5 \mathrm{k}$ & $51 \mathrm{i}$ & $360 \mathrm{f}$ & $36 \mathrm{j}$ & $1386 \mathrm{~b}$ \\
\hline \multirow{2}{*}{ A. ordifolia } & 0.1 & $32 \mathrm{j}$ & $86 \mathrm{~h}$ & $396 \mathrm{f}$ & $52 \mathrm{i}$ & $1469 \mathrm{a}$ \\
\hline Note: different letters denote significant differences (Turkey test, P<0.05) & 0.05 & $31 \mathrm{j}$ & $654 \mathrm{e}$ & $78 \mathrm{~h}$ & $1129 \mathrm{c}$ \\
\hline
\end{tabular}

Table 3. Allelopathy effect of $0.1 \mathrm{mg} / \mathrm{ml}$ dry alcohol extract of $L$. spectabilis and A. cordifolia on germination of mungbean seeds and seedling growth, after 5 days

\begin{tabular}{|c|c|c|c|c|c|c|c|}
\hline Plant & Mungbean & Control & Leave & Stem & Petal & Ovary & Stamen \\
\hline \multirow{4}{*}{ L. spectabilis } & Germination\% & $100 \mathrm{a}$ & $95 \mathrm{ab}$ & $95 \mathrm{ab}$ & $100 \mathrm{a}$ & $92 \mathrm{ba}$ & $100 \mathrm{a}$ \\
\hline & Shoot $(\mathrm{cm})$ & $0 \mathrm{~b}$ & $0 \mathrm{~b}$ & $0 \mathrm{~b}$ & $0 \mathrm{~b}$ & $0 \mathrm{~b}$ & $0.04 \mathrm{a}$ \\
\hline & Hypocotyle $(\mathrm{cm})$ & $0.75 \mathrm{e}$ & $1.85 \mathrm{a}$ & $0.5 \mathrm{f}$ & $1.25 \mathrm{c}$ & $0.89 \mathrm{~d}$ & $1.4 \mathrm{~b}$ \\
\hline & $\operatorname{Radicle}(\mathrm{cm})$ & $2.35 \mathrm{a}$ & $0.65 c$ & $1.75 b$ & $1.85 \mathrm{~b}$ & $1.83 \mathrm{~b}$ & $2.30 \mathrm{a}$ \\
\hline \multirow{4}{*}{ A. cordifolia } & Germination\% & 100 & $97 a$ & $94 \mathrm{ab}$ & $100 \mathrm{a}$ & $90 \mathrm{~b}$ & $100 \mathrm{a}$ \\
\hline & Shoot $(\mathrm{cm})$ & 0 & $0 \mathrm{~b}$ & $0 \mathrm{~b}$ & $0 \mathrm{~b}$ & $0 \mathrm{~b}$ & $0.1 \mathrm{a}$ \\
\hline & Hypocotyle $(\mathrm{cm})$ & $0.75 a$ & $0.1 \mathrm{~d}$ & $0.15 \mathrm{~d}$ & $1.35 b$ & $0.92 \mathrm{c}$ & $1.54 \mathrm{~b}$ \\
\hline & $\operatorname{Radicle}(\mathrm{cm})$ & $2.35 \mathrm{a}$ & $0.25 \mathrm{~d}$ & $0.27 \mathrm{~d}$ & $1.74 \mathrm{c}$ & $1.83 \mathrm{~b}$ & $2.27 \mathrm{a}$ \\
\hline
\end{tabular}

Note: different letters denote significant differences (Turkey test, $\mathrm{P}<0.05$ )

Table 4. Allelopathy effect of $0.1 \mathrm{mg} / \mathrm{ml}$ dry alcohol extract of $L$. spectabilis and $A$. cordifolia on germination of barely grain and seedling growth

\begin{tabular}{|c|c|c|c|c|c|c|c|}
\hline Plant & Barely & Control & Leave & Stem & Petal & Ovary & Stamen \\
\hline \multirow{3}{*}{ L. spectabilis } & Germination\% & $90 \mathrm{a}$ & $95 \mathrm{a}$ & $55 \mathrm{c}$ & $45 d$ & $83 b$ & $80 \mathrm{~b}$ \\
\hline & Shoot $(\mathrm{cm})$ & $3 a$ & 0.28 & $1.7 \mathrm{~b}$ & $0 \mathrm{~d}$ & $0.25 \mathrm{c}$ & $0.3 \mathrm{c}$ \\
\hline & Radicle $(\mathrm{cm})$ & $3.15 \mathrm{a}$ & $2 b$ & $2 b$ & $0.3 \mathrm{~d}$ & $1.5 \mathrm{c}$ & $1.1 \mathrm{c}$ \\
\hline \multirow{3}{*}{ A. cordifolia } & Germination\% & $90 \mathrm{a}$ & $55 \mathrm{c}$ & $53 \mathrm{c}$ & $39 \mathrm{c}$ & $79 \mathrm{~b}$ & $83 \mathrm{~b}$ \\
\hline & Shoot $(\mathrm{cm})$ & $3 a$ & $0.1 \mathrm{de}$ & $0.15 d$ & $0 \mathrm{e}$ & $0.96 \mathrm{~b}$ & $0.28 \mathrm{c}$ \\
\hline & Radicle $(\mathrm{cm})$ & $3.15 a$ & $0.15 \mathrm{~d}$ & $0.14 \mathrm{~d}$ & $0.1 \mathrm{~d}$ & $0.87 \mathrm{c}$ & $1.14 b$ \\
\hline
\end{tabular}

Note: different letters denote significant differences (Turkey test, $\mathrm{P}<0.05$ ) 


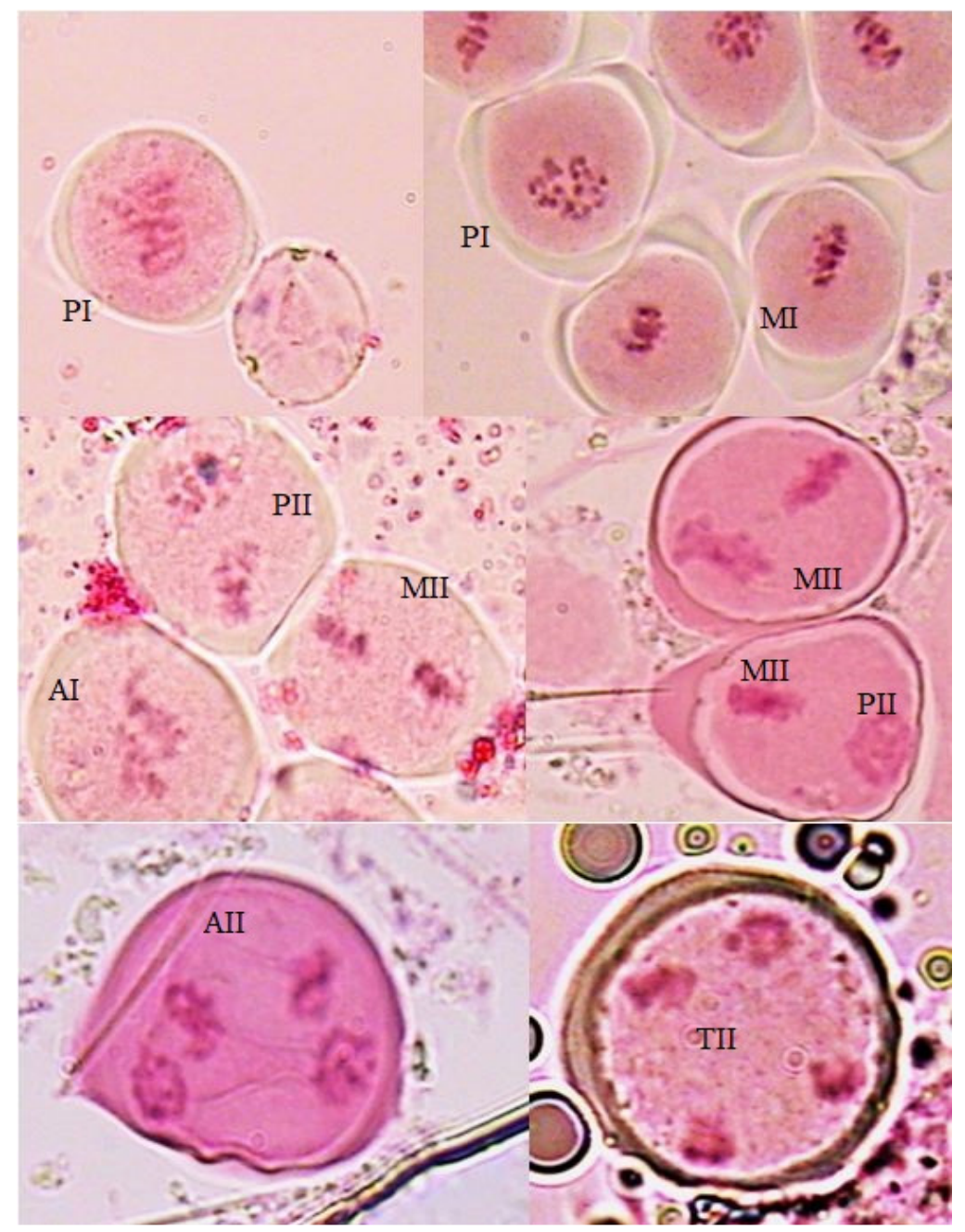

Fig 1. Meiotic stages of L. spectabilis: (PI) Prophase I: 9 compaction bivalent chromosomes. (MI) Metaphase I: 9 compaction bivalent chromosomes, stood at spindle equator. (AI) Anaphase I: dissociation of the 9 chromosomes shifting towards each spindle pole and Telophase I with two polar groups of chromosomes. (PII) prophase II: two groups of chromosomes. (MII) Metaphase II: two groups of compaction chromosomes at the spindle equators. (AII) Anaphase II: dissociation of chromatids towards each spindle pole. (TII) Telophase II: four groups of sister chromatids.

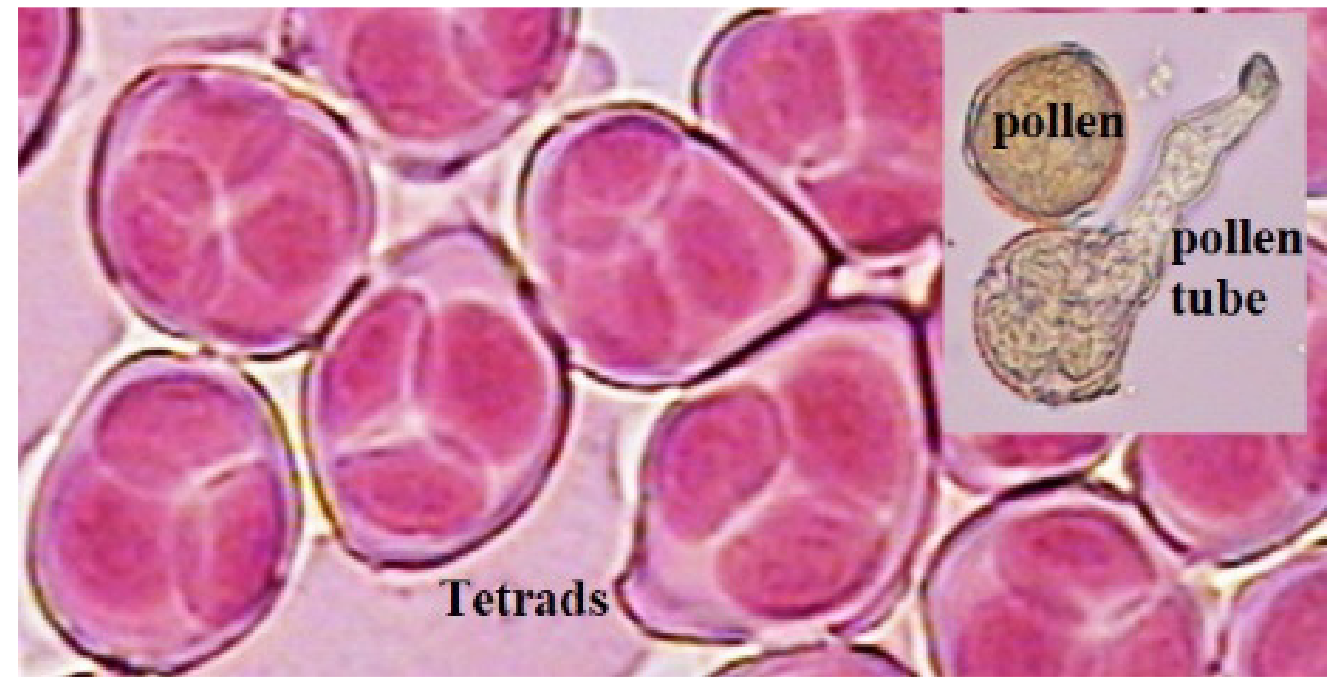

Fig. 2. Late telophase II of $L$. spectabilis: tetrad of four haploid nuclei ad adult pollen grain 


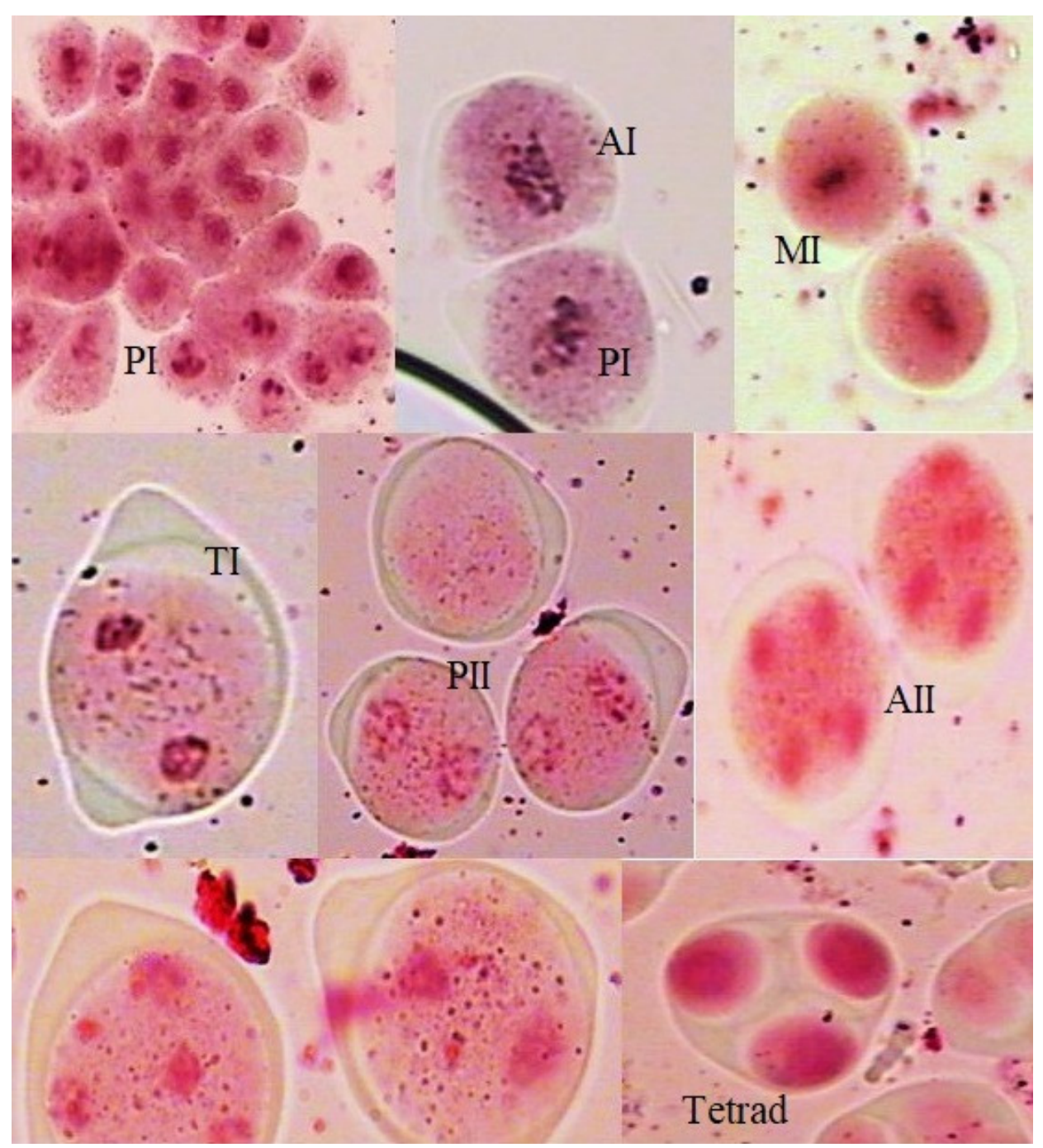

Fig 3. Meiotic stages of $A$. cordifolia: (PI) Prophase I, (MI) Metaphase I, (AI) Anaphase I, (TI) Telophase I, (PII) Prophase II, (MII) Metaphase II, (AII) Anaphase II and Tetrad

\section{Discussion}

Total phenols of the organs of $A$. cordifolia and $L$. spectabilis (syn: Mesembryanthemum spectabila) were 13.44 and $43.12 \mathrm{mg} / \mathrm{g}$, respectively. The leaf of Sesvium portulacastrum contained phenol $8.9 \mathrm{mg} / \mathrm{g}$ and a high antioxidant activity (Mohan, 2013) but it was lower than our results (leaf phenol=17.32 mg/g). All organs of M. edule showed a high antioxidant activity, with a considerable efficiency for stems followed by leaves and roots. The stems with $86.5 \mathrm{mg} / \mathrm{g}$ phenol and leaves with $68.7 \mathrm{mg} / \mathrm{g}$ phenol had the highest phenol content (Falleh et al., 2011). Nevertheless, in this study, phenol content of the organs of L. spectabilis and $A$. cordifolia were very lower than that of organs of M. edule.

In particular, the antioxidant activity was higher in the stamens than in the other organs, and this difference seems to be due to the presence of betacyanins in organs of plants species of Aiozaceae family as shown by Piatteli and Impellizzeri (1969). Nevertheless, some of them did not show any significant antioxidant and toxicity activities (Samy et al., 2018). The greatest antioxidant activity was found in organic solution extracts of M. crystallinum and Carpobrotus edulis (Bouftira et al., 2009). In this study, the alcoholic extract of the stamens had the highest antioxidant activity. Allelopathy effects of $L$. spectabilis and A. cordifolia were associated with small inhibitory effects on seed germination and seedlings growth of mungbaen. Allelopathic effects of both plant extracts, in particular $A$. cordifolia, were significant on barley seed germination and growth of seedlings. The extracts of Triantheum portulacastrum (Aizoaceae) reduced seed germination and seedling growth of Sesamum indicum (Huang et al., 2017). Different extracts of Cassia tora organs inhibited seed germination and seedling growth of mustard (Sarkar $e t$ al.,) of mustard (Sarkar et al., 2012). The strength of the allelopathic effects of roots', leaves' and stems' extracts of $A$. philoxeroides on $Z$. matrella diminished subsequently (Huang et al., 2017) but no information was found about the allelopathic effects of $L$. spectabilis and $A$. cordifolia. 
1364

The number of chromosomes in meiosis revealed that the number of chromosomes of $A$. cordifolia is $n=6(2 n=12)$ and $\mathrm{n}=9 \quad(2 \mathrm{n}=18)$ for $L$. spectabilis (syn: mesembryanthemum spetabila). The meiosis number of chromosomes in 12 genera of Mesembryanthemum was found to $\mathrm{n}=9$ (Sugiura, 1940). M. crystallinum and $M$. froskaoli had $2 \mathrm{n}=18$ in mitosis division (Soliman et al., 2017). The meiosis of $A$. cordifolia and L. spectabilis was normal and the chromosomes were very small. The results of Pagliarini (1990) indicated that $A$. cordifolia was abnormal in terms of the meiosis's process of pollen mother cells. On the other hand, our results suggested that meiosis stages are normal for both plants. In pollen mother cells division of $L$. spectabilis and $A$. cordalis, all stages of meiosis I and II were observed (Dawe, 1998).

\section{Conflict of Interest}

The authors declare that there are no conflicts of interest related to this article.

\section{References}

Braun P, Winkelmann T (2016). Localization and overcoming of hybridization barriers in Delosperma and Lampranthus (Aizoaceae). Euphytica 211(2):255-275.

Dawe RK (1998). Meiosis chromosome organization and segregation in plants. Annual Review of Plant Biology 49(1):371-395.

Delgado-Vargas F, Jimenes AR, Paredes-Lepez O (2000). Natural pigments: carotenoids, anthocyanins, and betalains. Critical Reviews in Food Science and Nutrition 40(3):173-289.

Dellagareca M, Fiorentino A, Izzo A, Napoli F, Purcaro R, Zarrelli A (2007). Phytotoxicity of secondary metabolites from $A$. cordifolia. Chemistry andBiodiversity 4:118-129.

Falleh H, Ksouri R, Medini F, Guyot S, Abdelly C, Mangne C (2011). Antioxidant activity and phenolic composition of the medicinal and edible halophyte Mesembryanthmum edule L. Industrial Crops and Products34(1):1066-1071.

Gopala-Krishnan R, Nayar NM, Samath S (1964). Cytogenetic studies of two amphidiploids in the genus Oryza. Euphytica 13(1):57-64.

Huang Y, Ge Y, Wang Q, Zhou H, Liu W, Christie P (2017). Allelopathic effects of extracts Alternanthera philoxeroides on growth of Zoysia matrella. Polish Journal of Environmental Study 26(1):97-105.
Ibtissem B, Abdelly C, Sfar S (2009). Antioxidant propertis of Mesembryanthmum crystallinm and Carpobrotus edulis extracts. Asian Journal ofChemistry21(1):359-365.

Li ZH, Wang Q, Pan CD, Jiang DA (2010). The phenolics and plant allelopathic. Molecules 15(12):8933-8952.

Mohan VR (2013). Total phenolic content and total flavonoid content of Sesuvium portulacastrum. Journal of Advanced Pharmacy Education and Research 13(2):69-73.

Moyo B, MukanganyamaS (2015). The antifungal and toxicity properties of Lampranthus francisci. Journal of Mycology 898202:1-15.

Novoa A, Gonzalez L, Moravcova L, Pysek P (2012). Effects of soil charactrestic, allelopathy and frugivorous on establishment of the invasive plant Carpobroutus edulis. PLoSOne 7(12):e53166.

Pagiarini MS (1990). Meiosis behavior and pollen fertility in Apenia cordifolia. Caryologia 43(2):157-162.

Park MJ, Han KS, Kim JW, Park JH, Shin HD (2016). Pythium aphanidermatum causing Pythium rot on Lampranthus spectabilis in Korea. Journal of Phytopathology 164(7-8):567-570.

Piatteli M, Impellizzeri G (1969). Betacyanins from Lampranthus sp. (Aizoaceae). Phytochemistry 8(8):1595-1596.

Samy MN, Khalil HE, Sugimoto S, Otsuka H, Matsunami K, Kamel MS (2018). Phyto compounds of aerial parts of Lampranthus spectabilis. South Africa Journal of Botany 118:179-182.

Sarkar E, Chatterjee SN, Chakraborty P (2012). Allelopathic effect of Cassia tora on seed germination and growth of mustard. Turkish Journal of Botany 36(5):488-494.

Singleton VL, Rossi JA (1965). Colorimetry of the total phenolic with phosphomolibdate and phosphotungstate reagents. American Journal of Enology and Viticulture 16(3):144158.

Soliman MI, Zaghloul MS, Heikal YS (2017). Comparative karyotype of three Mesembryanthemum (Aizoaceae) species in Egypt. Journal Of Modern Science \& Engineering 1(3):72-89.

Sugiura T (1940). Studies on the chromosomes number in higher plants. Cytologia 10(3):364 370.

Xiao Z, Wang Y WangJ, Li P, Ma F (2019). Structure antioxidant capacity relationship of dihyrochlalcone compounds in Malus. Food Chemistry 275:354360. 